\title{
Effects of Celery Seed Extracts on Some Haematological and Biochemical Parameters in Albino Rats Treated with Gentamicin
}

\author{
Tavga Ismael Mustafa \\ Department of Biology \\ Faculty of Science \\ Soran University \\ Soran, Iraq \\ tavga.ismael96@gmail.com
Nazar Mohammed Shareef Mahmood
Department of Biology
Faculty of Science
Soran University
Soran, Iraq \\ nazar.mahmood@soran.edu.iq

$$
\begin{aligned}
& \text { Kurdo Bapir Chato } \\
& \text { Department of Biology } \\
& \text { Faculty of Science } \\
& \text { Soran University } \\
& \text { Soran, Iraq } \\
& \text { kurdo.chato@soran.edu.iq }
\end{aligned}
$$

\author{
Zhakaw Khudir Abdullah \\ Department of Biology \\ Faculty of Science \\ Soran University \\ Soran, Iraq \\ zhakawkhudir@gmail.com
}
Shorish Mustafa Abdullah Gorony
Department of Biology
Faculty of Science
Soran University
Soran, Iraq
shorish.gorony@soran.edu.iq

Ranjbar Muksy Mohammed Shareef

Department of Biology

Faculty of Science

Soran University

Soran, Iraq

ranjbar.muksy@gmail.com
Volume 4 - Special

Issue: 3rd International

Conference on Health \&

Medical

Sciences:

Insight into Advanced

Medical

(ICHMS 2019)

DOI:

10.24017/science.2019

.ICHMS.12

Received:

25 May 2019

Accepted:

2 July 2019
Abstract

The present study targeted the influence of orally celery seeds (Apium graveolens) aqueous extract and ethanolic extracts on male albino rats injected with gentamicin intraperitoneally to investigate some hematological and biochemical parameters. Thirty-two male rats were weighing 300-400 gm carried out for the present research, they controlled environmentally. Animals were divided equally and randomly into four groups each of which contained eight rats. First group (control) included normal rats, group2 were given $100 \mathrm{mg} / \mathrm{kg} \mathrm{B.W.} \mathrm{gentamicin}$ (GM) intraperitoneally (IP), group3 (combined group) were given $100 \mathrm{mg} / \mathrm{kg}$ B.W. GM and $150 \mathrm{mg} / \mathrm{kg}$ B.W. celery seed ethanolic extract orally by needle gavage, and group4 (combined group) were given $100 \mathrm{mg} / \mathrm{kg}$ B.W. GM (IP) and celery seeds aqueous extract $150 \mathrm{mg} / \mathrm{kg}$ B.W. orally by needle gavage respectively the present study contiued for eight executive days. The results showed that the elevated by GM haematological parameters lowered by the celery seed aqueous extract as compared to the celery seed ethanolic extract group, while the elevated serum malondialdehyde (MDA) and total cholesterol (TC) are decreased in group3 more than they were in the group4, in contrast to that the triglyceride (TG), high density lipoprotein 


\begin{abstract}
(HDL), low-density lipoprotein (LDL), serum creatinine (CR), serum uric acid (UA), and alkaline phosphatase (ALP) lowered in the group 4 from the group 3 . The present study concluded that both extracts of celery seeds play a vital biological role, including the improvement effects against the side effect of GM and offering health benefits through decreasing of elevated parameters.
\end{abstract}

Keywords: celery seed, gentamicin, ethanolic extract, aqueous extract.

\title{
1. INTRODUCTION
}

The health benefits attention and high positive influences of medicinal plants has been augmented, because of their extensive use in the therapeutic agents and preventions of multiple diseases. Celery (Apium graveolens) and their extracts have a vast history uses in many cultures to treat joint pain, gout, hysteria, nervousness, headache, weight loss due to malnutrition, loss of appetite, and exhaustion. Celery is also used to promote relaxation and sleep; to kill bacteria in the urinary tract; as a digestive aid. In one attempt it has been demonstrated that female rats were induced haematologcal toxicity by carbon tetrachloride and treated with aqueous extract of celery seeds showed important effect in recovery of the hematological parameters [1]. Therefore, this study is aimed to investigate the influence of two different extracts (ethanolic and aqueous) of celery seeds on male rats treated with GM on some hematological and biochemical parameters.

\section{LITERATURE REVIEW}

It has been reported that animals were gavaged at doses of 213 and $425 \mathrm{mg} / \mathrm{kg}$ B.W. of celery seeds for sixty consecutive days revealed good hypolipideamic effects including a decrease of serum TC, TG, LDL, and significant increase in HDL [2]. Feeding diet supplemented with $10 \%$ of celery, lowered the elevated serum level of liver enzymes (aspartate aminotransferase, alanine aminotransferase, and alkaline phosphatase) and blood lipids in rats [3]. Rats were exposure to gentamicin (GM) can induce significant histological alterations in the kidney as well as remarkable blood chemical changes that might indicate marked renal failure [4]. It is well established that rats were injected with gentamicin sulfate $(100 \mathrm{mg} / \mathrm{kg} / \mathrm{day}$ i.p. $)$ induced nephrotoxicity which distinguished by an elevation in blood urea nitrogen, serum CR concentration and MDA [5]. At the cell level GM appears to bind to anionic phospholipids of the cell membrane, remarkably to phosphatidylinositol 4, 5-bisphosphate, and rewards access to the cell interior. After internalization, GM binds to subcellular organelles or is taken up into lysosomes. Accumulation of aminoglycosides within the renal cortex is known to be related intimately to the pathogenesis of nephrotoxicity. Although the mechanism of gentamicininduced cell injury and cell death is still unclear, interactions with the cell membrane, mitochondria, lysosomes and microsomes are likely to be involved [6]. The same attempt reported that GM administration to rats at doses of $20,40 \mathrm{or} 80 \mathrm{mg} \mathrm{kg} / \mathrm{kg}$ B.wt./ day for 6 days induced nephrotoxicity exhibited by elevated plasma CR concentration and a decrease in kidney cortex ALP activity [7]. Meanwhile it has been demonstrated that rats received GM at $100 \mathrm{mg} / \mathrm{kg} / \mathrm{d}$; elevated lipid profile include TG, TC, LDL, VLDL and HDL [8] and [7]. Nephrotoxicity induced by GM is a complex phenomenon characterized by an increase in plasma lipid peroxidation and decrease catalase, glutathionepeoxidase and glutathione [9]. Furthermore it has been showed that the toxicity of GM is believed to be related to the generation of reactive oxygen species (ROS) in the kidney [10]. 


\section{METHODS AND MATERIALS}

\section{Preparations of laboratory animals}

Male albino rats (Rattus norvegicus) were purchased from animal house (Zakho UniversityIraq) and they were housed in animal house (Biology department of Faculty of science, Soran University, Iraq). The present study was performed thirty-two male albino rats. Animals were weighting about $300-400$ gm. They acclimatized in an environmentally controlled room at constant temperature $22 \pm 2{ }^{\circ} \mathrm{C}$ on a lighting schedule $12 \mathrm{~h}$ light and $12 \mathrm{~h}$ darkness, they were maintained at free access to tap water ad libitum they fed at a standard pelleted feed according to Pico Lab. During the experiment the cages were cleaned once a week.

\section{Preparation of the diet}

The constituents of diet were determined according Pico Lab. Rodent diet 20, with assistance of expert of in Erbil poultry project and Erbil animal diet factory, Iraq, as following; wheat $66.6 \%$, soya $25.6 \%$, oil sun flower $4.4 \%$, lime stone $1.5 \%$, salt $0.63 \%$, methionine $0.156 \%$, lysine $0.244 \%$, choline chloride $0.062 \%$, vit CX lay $0.058 \%$, dicalcium phosphate $0.642 \%$, AZ $/ 1200=0.080 \%$ and trace elements $0.050 \%$.

\section{Preparation gentamicin dose}

Gentamicin ampules were purchased in the local pharmaceutical were the patients used them as an antibiotics against disease related with respiratory system, the dose of $80 \mathrm{mg} / \mathrm{kg} \mathrm{B.W}$. was determined and injected intraperitoneally (IP) daily for eight executive days.

\section{Preparation of celery seeds extract doses}

The celery seeds were obtained from the local markets, after they were washed, dried, crashed and dissolved into two solvents (ethanol and aqueous) then the solvents evaporated by rotary evaporator vacuum system till the crude obtained (Butters \& Whitehouse, 2003). The doses celery seeds were prepared according to the previous study and the moderate doses of 150 $\mathrm{mg} / \mathrm{kg}$ B.W. were selected against the model group (gentamicin group) orally by needle gavage daily for eight executive days.

\section{Experimental design}

Group 1 (control): Rats were given, normal diet and tap water ad libitum.

Group 2: Rats were given normal diet, tap water ad libitum and $80 \mathrm{mg} / \mathrm{kg}$ B.W. of GM daily by IP injection.

Group 3: Rats were given normal diet, tap water ad libitum and $80 \mathrm{mg} / \mathrm{kg}$ B.W. of GM daily by IP injection and $150 \mathrm{mg} / \mathrm{kg}$ B.W. of ethanolic celery seed extract daily orally by needle gavage. Group 4: Rats were given normal diet, tap water ad libitum and $80 \mathrm{mg} / \mathrm{kg}$ B.W. of GM daily by intraperitoneal injection. And $150 \mathrm{mg} / \mathrm{kg}$ B.W. of aqueous celery seed extract daily orally by gavage.

\section{Collection of blood samples}

At the end of experiment the rats underwent fasting $24 \mathrm{~h}$, then rats anesthetized with ketamine hydrochloride $0.8 \mathrm{ml}$ and xylazine $0.2 \mathrm{ml}$. Blood samples, were taken by cardiac puncture into chilled tubes with or without ethylene diamine tetra acetic acid (EDTA) as anticoagulant, then centrifuged at $3000 \mathrm{rpm}$ (revolution per minute) for $15 \mathrm{~min}$.

\section{Measurement of hematological parameters}

Hematological parameters (Hb, RBC, WBC, HCT and MCV) were measured by coulter counter for each group.

\section{Determination of serum malondialdehyde}

Serum MDA concentration, was determined spectrophotometrically, $150 \mu \mathrm{L}$ serum sample the followings were added: $1 \mathrm{ml}$ of $17.5 \%$ trichloroacetic acid and $1 \mathrm{ml}$ of $0.66 \%$ thiobarbituric acid, mixed well by vortex, incubated in boiling water for $15 \mathrm{~min}$, and then allowed to cool. One $\mathrm{ml}$ of $70 \%$ trichloroacetic acid was added and the mixture was allowed to stand at room temperature for $20 \mathrm{~min}$, and then centrifuged at $2000 \mathrm{rpm}$ for $15 \mathrm{~min}$, and the supernatant was taken for scanning spectrophotometrically at 532nm [11].

The MDA concentration was calculated with equation mentioned with number1.

\section{Measurement of lipid profile parameters}


Serum total cholesterol, TG, HDL and LDL were measured by the enzymatic colorimetric test -CHOD-PAP Method according to the laboratory kit obtained from (Centronic GmbH, Germany).

\section{Measurement of liver function test and kidney function parameters}

Serum parameters of liver function test included GPT and ALP and kidney function test included CR and UA were measured with automatic instrument in the Ashti Hospital, Soran, Iraq.

\section{Statistical analysis}

The data were analyzed statistically by one-way analysis of variance (ANOVA) and Duncan test as a post hoc using statistical package for the social sciences (SPSS) version 16.0 with significant level fixed at $\mathrm{p}<0.05$. Data were expressed as mean \pm standard error (mean \pm S.E.).

\section{RESULTS}

\section{Effect of gentamicin with different seed celery extracts on some hematological parameters in rats}

The influence of gentamicin with different seed celery extracts on some hematological parameters in rats is shown in table 1. WBC, RBC and $\mathrm{Hb}$ are increased significantly $(\mathrm{p}<0.05)$ in gentamicin groups as compared to control group. On the other hand both seed celery extracts exerted their effect non-significantly on the same parameters as compared to gentamicin group. Besides that non-significant changes occurred in other haematological parameters from model and both extracts.

Effect of gentamicin with different seed celery extracts on lipid profile and Malondialdehyde parameters in rats

The influence of gentamicin with different seed celery extracts on lipid profile and MDA parameters in rats is shown in table 2. TG was increased significantly $(\mathrm{p}<0.05)$ in a GM group as compared to the control, while other parameters increased non-significantly. In contrast all parameters except LDL decresed non-significantly in rats treated with GM and celery seed ethanolic extract as compared to GM group, whereas celery seed aqueous extract caused a significant $(\mathrm{p}<0.05)$ decrease of TG and non-significant decrease of other parameters except MDA and TC as compared to GM group.

\section{Effect of gentamicin with different seed celery extracts on kidney function tests in rats}

The influence of gentamicin with different seed celery extracts on CR and UA parameters in rats is shown in table 3. The administration of GM increased CR level significantly $(p<0.05)$ as compared to control group, while the UA level increased non-significantly as compared to control. In contrast the non-significant decrease of CR and UA level were occurred in both seed celery extract groups as compared to gentamicin group.

\section{Effect of gentamicin with different seed celery extracts on liver function tests in rats}

The influence of gentamicin with different seed celery extracts on creatinine and uric acid parameters in rats is shown in table 4. Rats treated with gentamicin showed non-significant decrease in the level of GPT, and ALP as compared to control groups, meanwhile both extracts decreased GPT and ALP levels non-significantly as compared to gentamicin group.

\section{DISCUSSION}

The present study was aimed to ameliorate the renal toxicity of a commonly used aminoglycoside antibiotic GM with the administration of ethanolic and aqueous seed celery extracts. Celery is a widely used herbal spice of Southeast Asia and the Middle East, which has been renowned for its various beneficial effects in the human. Hematological components are usually contemplating the physiological responsiveness of the animal to its external and internal environments and this is serving as a genuine tool for monitoring animal health [12]. 
Exposure of human body to harmful substances could produce adverse effect in multiple organ systems and cause morphological, biochemical and physiological changes, including alteration of kidney function and haematological disorders [13]. The significant increase of RBC parameter in rats treated with gentamicin in the present study (table 1) is supported by the finding of [12] who reported that rats received GM $100 \mathrm{mg} / \mathrm{kg}$ BW intramuscularly for the last 5 days led to increase RBC. Also the gentamicin administration caused a significant increase in WBC (table 1). The mechanism is not known, however, it could be due to chronic inflammatory response which was characterized by diffuse infiltration of lymphocytic inflammatory cells in kidney tissues. On the other hand both extracts provoke their effects on hematological parameters non-significantly against GM administration (table 1). The aqueous extract of celery seed effect is in agreement with finding of [1] who reported that female rats treated with $200 \mathrm{mg} / \mathrm{kg}$ of B.W. seed celery aqueous extract against carbon tetrachloride intraperitoneally led to non-significant differences in hematological parameters. In the current study, one of the causes of GM induced renal damage is oxidative stress. This view is supported by a significant elevation in the serum levels of MDA as reflected by an increase in Thiobarbituric acid reactive substances (TBARS) which is an end product of lipid peroxidation. The same results were also showed in other study [14] who showed that male rats treated with GM (100 mg / kg of B.W.) (i.p). led to increase MDA level. Also the same results of MDA were observed in both extracts administration. The present study demonstrated that GM treatment caused non-significant increases in the serum cholesterol and LDL, and significant increases in TG concentrations this elevation is in agreement with [15] who reported that treatment of rats with GM $(80 \mathrm{mg} / \mathrm{kg})$ increased the levels of TC and LDL significantly, TG and LDL in serum as compared with control animals. Also, the same agreement is confirmed with the finding of [16] on Guinea Pigs (Cavia porcellus) treated with GM (100 mg/kg B.W./day) for 10 days IP. In the present work we found it of interest to determine the concentration of CR and uric acid in plasma of gentamicin-treated rats because of the close relationship between the antibiotic's nephrotoxicity and those parameters, therefore the significant increase of CR in rats treated with gentamicin is supported by the finding of [17] who demonsrated that rats given the GM intramuscularly in doses of 20, 40, and $80 \mathrm{mg} / \mathrm{kg} /$ day for 6 days caused significant increase in CR, besides that the non-signficant change in uric acid in uric acid is in agreement with previous study of [17] who reported that male rats received gentamicin intraperitoneally for 9 days produced not provoke changes. The non-significant decrease of uric acid and CR in rats treated with seed celery (ethanolic and aqueous extract) are supported by the finding of the study of [18] who demonstrated that male rats administrated with seed celery extract cause elevation of uric acid and CR levels. In the present study the non-significant reduce of GPT and ALP in rats treated with GM is in agreement with study of [4] who showed that male rats were exposed to G4 revealed a decrease in liver parameters, as well as the both extracts of seed celery caused non-significant decrease of liver. This study recommends that dietary intake of plant concentration can be beneficial to patients suffering from hypercholesterolemia and liver diseases [3]. 


\begin{tabular}{|c|c|c|c|c|c|}
\hline Groups & $\begin{array}{c}\text { WBC* } \\
\left(\times 10^{3} / \mu L\right)\end{array}$ & $\begin{array}{c}\text { RBC* } \\
\left(\mathbf{x} 10^{6} / \mu L\right)\end{array}$ & $\begin{array}{c}\mathrm{Hb}^{*} \\
(\mathrm{gm} / \mathrm{dL})\end{array}$ & $\begin{array}{c}\text { HCT }^{*} \\
(\%)\end{array}$ & $\begin{array}{l}\text { MCV } \\
\text { (fL) }\end{array}$ \\
\hline Control & $\begin{array}{l}3.957 \pm \\
0.765^{\mathrm{a}}\end{array}$ & $\begin{array}{l}6.681 \pm \\
0.457^{a}\end{array}$ & $\begin{array}{l}12.15^{ \pm} \\
0.937^{\mathrm{a}}\end{array}$ & $\begin{array}{l}35.27 \pm \\
2.927^{\mathrm{a}}\end{array}$ & $\begin{array}{l}52.45 \pm \\
1.149^{\mathrm{a}}\end{array}$ \\
\hline GM & $\begin{array}{l}7.620 \pm \\
0.522^{b}\end{array}$ & $\begin{array}{l}8.073 \pm \\
0.129^{b}\end{array}$ & $\begin{array}{l}15.73 \pm \\
0.292^{b}\end{array}$ & $\begin{array}{l}43.12 \pm \\
0.855^{\mathrm{ab}}\end{array}$ & $\begin{array}{l}53.41 \pm \\
0.547^{\mathrm{a}}\end{array}$ \\
\hline $\begin{array}{c}\text { GM } \\
+ \\
\text { Ethanolic } \\
\text { extract }\end{array}$ & $\begin{array}{l}9.800 \pm \\
1.347^{b}\end{array}$ & $\begin{array}{l}8.130 \pm \\
0.166^{b}\end{array}$ & $\begin{array}{l}15.95 \pm \\
0.322^{b}\end{array}$ & $\begin{array}{l}44.08 \pm \\
0.944^{b}\end{array}$ & $\begin{array}{l}54.21 \pm \\
0.776^{a}\end{array}$ \\
\hline $\begin{array}{c}\text { GM } \\
+ \\
\text { aqueous } \\
\text { extract }\end{array}$ & $\begin{array}{l}7.025 \pm \\
1.430^{\mathrm{ab}}\end{array}$ & $\begin{array}{l}7.770 \pm \\
0.52^{\mathrm{ab}}\end{array}$ & $\begin{array}{l}14.100 \pm \\
1.057 \mathrm{ab}\end{array}$ & $\begin{array}{l}42.625 \pm \\
3.817^{\mathrm{ab}}\end{array}$ & $\begin{array}{r}54.600 \pm \\
1.358^{\mathrm{a}}\end{array}$ \\
\hline
\end{tabular}

Table 1: Effect of gentamicin with different seed celery extracts on some hematological parameters in rats.

Data presented as mean \pm S.E the same letters mean non-significant differences while the different letters mean significant differences $*=\mathrm{p}<0.05$

Table 2: Effect of gentamicin with different seed celery extracts on lipid profile and MDA parameters in

\begin{tabular}{|c|c|c|c|c|c|}
\hline Parameters & $\begin{array}{c}\mathrm{MD}^{*} \\
(\mathrm{nmol} / \mathbf{L})\end{array}$ & $\begin{array}{c}\text { TC * } \\
\text { (mg/dL) }\end{array}$ & $\begin{array}{c}\text { TG* } \\
\text { (mg/dL) }\end{array}$ & $\begin{array}{c}\text { HDL* }^{*} \\
\text { (mg/dL) }\end{array}$ & $\begin{array}{c}\text { LDL* } \\
\text { (mg/dL) }\end{array}$ \\
\hline \multicolumn{6}{|l|}{ Groups } \\
\hline Control & $\begin{array}{l}9.350 \pm \\
2.436^{\mathbf{a}}\end{array}$ & $\begin{array}{l}70.9 \pm \\
1.856^{\mathbf{a}}\end{array}$ & $\begin{array}{l}54.50 \pm \\
0.957^{\mathrm{a}}\end{array}$ & $\begin{array}{l}36.500 \pm \\
0.5627^{a}\end{array}$ & $\begin{array}{l}26.66 \pm \\
0.210^{a}\end{array}$ \\
\hline GM & $\begin{array}{l}21.37 \pm \\
2.765^{\text {ab }}\end{array}$ & $\begin{array}{l}82.68 \pm \\
5.880^{\mathrm{a}}\end{array}$ & $\begin{array}{l}79.16 \pm \\
6.862^{\mathbf{b}}\end{array}$ & $\begin{array}{l}37.00 \pm \\
2.081^{\mathrm{ab}}\end{array}$ & $\begin{array}{l}32.00 \pm \\
2.422^{\text {ab }}\end{array}$ \\
\hline $\begin{array}{c}\text { GM } \\
+\end{array}$ & $\begin{array}{l}19.04 \pm \\
3.22^{\mathbf{a b}}\end{array}$ & $\begin{array}{l}45.93 \pm \\
8.173^{a}\end{array}$ & $\begin{array}{l}69.83 \pm \\
5.41^{\mathrm{ab}}\end{array}$ & $\begin{array}{l}46.00 \pm \\
2.000^{\mathbf{a b}}\end{array}$ & $\begin{array}{l}39.33 \pm \\
1.763^{\mathrm{ab}}\end{array}$ \\
\hline \multicolumn{6}{|l|}{$\begin{array}{l}\text { Celery seed } \\
\text { ethanolic } \\
\text { extract }\end{array}$} \\
\hline $\begin{array}{c}\text { GM } \\
+ \\
\text { Celery seed } \\
\text { aqueous extract }\end{array}$ & $\begin{array}{l}37.54 \pm \\
1.654^{\mathbf{b}}\end{array}$ & $\begin{array}{c}79.87 \pm \\
5.501^{\mathrm{b}}\end{array}$ & $\begin{array}{l}53.500 \pm \\
4.6636^{\mathbf{a}}\end{array}$ & $\begin{array}{l}38.750 \pm \\
3.1983^{\mathbf{b}}\end{array}$ & $\begin{array}{l}31.250 \pm \\
3.1983^{\mathbf{b}}\end{array}$ \\
\hline
\end{tabular}

Data presented as mean \pm S.E the same letters mean non-significant differences while the different letters mean significant differences $*=\mathrm{p}<0.05$ 
Table 3: Effect of gentamicin with different seed celery extracts on creatinine and uric acid in rats.

\begin{tabular}{|c|c|c|c|c|}
\hline Parameters & Control & GM & $\begin{array}{c}\text { GM } \\
+ \\
\text { Celery ethanolic } \\
\text { extract } \\
\end{array}$ & $\begin{array}{c}\text { GM } \\
+ \\
\text { Celery aqueous } \\
\text { extract } \\
\end{array}$ \\
\hline Creatinine (mg/dL) & $\begin{array}{l}0.6525 \pm \\
0.0085^{a}\end{array}$ & $\begin{array}{l}4.5400 \pm \\
0.5838^{\mathbf{b}}\end{array}$ & $\begin{array}{l}3.0717 \pm \\
0.721^{\mathbf{a b}}\end{array}$ & $\begin{array}{l}4.0325 \pm \\
1.3344^{\mathbf{b}}\end{array}$ \\
\hline Uric acid (mg/dL) & $\begin{array}{l}1.0250 \pm \\
0.0924^{\mathrm{a}}\end{array}$ & $\begin{array}{l}1.6283 \pm \\
0.2054^{\mathbf{a}} \\
\end{array}$ & $\begin{array}{l}1.3333 \pm \\
0.1486^{a} \\
\end{array}$ & $\begin{array}{l}1.3300 \pm \\
0.1960^{\mathrm{a}} \\
\end{array}$ \\
\hline
\end{tabular}

Data presented as mean \pm S.E the same letters mean non-significant differences while the different letters mean significant differences $*=\mathrm{p}<0.05$

Table 4: Effect of gentamicin with different seed celery extracts on glutamate-pyruvate transaminase and alkaline phosphatase in rats.

\begin{tabular}{|c|c|c|c|c|}
\hline Groups & Control & GM & $\begin{array}{c}\text { GM } \\
+ \\
\begin{array}{c}\text { Celery ethanolic } \\
\text { extract }\end{array} \\
\end{array}$ & $\begin{array}{c}\text { GM } \\
+ \\
\text { Celery aqueous } \\
\text { extract } \\
\end{array}$ \\
\hline GPT (U/L) & $\begin{array}{l}12.500 \pm \\
0.6455^{\mathrm{a}}\end{array}$ & $\begin{array}{l}11.666 \pm \\
1.1737^{\text {a }}\end{array}$ & $\begin{array}{l}11.666 \pm \\
0.8819^{a}\end{array}$ & $\begin{array}{l}10.000 \pm \\
1.2247^{\text {a }}\end{array}$ \\
\hline $\operatorname{ALP}(\mathbf{U I} / \mathbf{L})$ & $\begin{array}{l}2.8700 \pm \\
0.9013^{\mathrm{a}}\end{array}$ & $\begin{array}{l}2.4617 \pm \\
1.6529^{a}\end{array}$ & $\begin{array}{l}1.8600 \pm \\
0.9670^{\mathrm{a}}\end{array}$ & $\begin{array}{l}1.7250 \pm \\
0.9650^{\mathrm{a}}\end{array}$ \\
\hline
\end{tabular}

Data presented as mean \pm S.E the same letters mean non-significant differences while the different letters mean significant differences $*=\mathrm{p}<0.05$

\section{Equations}

MDA calculation

$M D A\left(\frac{n m o l}{L}\right)=\frac{\text { absorbance at } 532 \mathrm{~nm}}{L \times E o} \times D \times 10^{6}$

Were:

L: light path $(1 \mathrm{~cm})$

E0: Extinction coefficient 1.56×105 M-1 .Cm-1

D: Dilution factor $=1 \mathrm{ml} \mathrm{Vol}$. Used in ref. $/ 0.15=6.7$

\section{CONCLUSION}

In view of the results and their interpretations we concluded that; the administration of GM intraperitoneally elevated the haematological parameters, MDA, lipid profile and kidney function test, whereas it provoke a declination in the liver function tests. Both ethanolic and aqueous extract of seed celery extracts (Apium graveolens L.) produced significant antioxidant activity against GM through different parameters. But aqueous extract showed higher 
recovering effect than the ethanolic extract in the haematological parameters. However the influence of ethanolic extract is more than the aqueous extract in some parameters as well as three rats had died in the group of aqueous extract of seed celery treatment may attributed that the seed treated with some or herbicide pesticide during their cultivation. Therefore, the mass in stomach was observed of in those rats during anatomy.

In contrast the recovered degree was observed in a high level of kidney function tests in the ethanolic extract than the aqueous extract. In contrast the both extracts provoked their effect in low recover state on the liver function test.

\section{REFERENCE}

[1] O. S. Khuon, "Role of Aqueous Extract of Apium graveolens Seeds Against the Haematotoxicity Induced by Carbon Tetrachloride," Journal of College of Education for Pure Science, vol. 2, no. 1, pp. 10-23, 2012.

[2] K. Mansi, A. M. Abushoffa, A. Disi, and T. Aburjai, "Hypolipidemic effects of seed extract of celery (Apium graveolens) in rats," Pharmacognosy magazine, vol. 5, no. 20, p. 301, 2009.

[3] N. M. A. El-Mageed, "Hepatoprotective effect of feeding celery leaves mixed with chicory leaves and barley grains to hypercholesterolemic rats," Pharmacognosy magazine, vol. 7, no. 26, p. 151, 2011.

[4] S. Alarifi et al., "Blood chemical changes and renal histological alterations induced by gentamicin in rats," Saudi journal of biological sciences, vol. 19, no. 1, pp. 103-110, 2012.

[5] A. Ateşşahin, I. Karahan, S. Yilmaz, A. Çeribaşi, and I. Princci, "The effect of manganese chloride on gentamicin-induced nephrotoxicity in rats," Pharmacological research, vol. 48, no. 6, pp. 637-642, 2003.

[6] R. Cronin and W. Henrich, "Toxic nephropathy," The kidney, vol. 2, pp. 1680-1711, 1996.

[7] A. Abdel-Gayoum, B. Ali, K. Ghawarsha, and A. Bashir, "Plasma lipid profile in rats with gentamicininduced nephrotoxicity," Human \& experimental toxicology, vol. 12, no. 5, pp. 371-375, 1993.

[8] H. Ahmadvand et al., "Effects of oleuropein on lipid peroxidation, lipid profile, atherogenic indices, and paraoxonase 1 status in gentamicin-induced nephrotoxicity in rats," ARYA Atherosclerosis, vol. 11, no. 2, p. 153,2015

[9] R. Manikandan, M. Beulaja, R. Thiagarajan, A. Priyadarsini, R. Saravanan, and M. Arumugam, "Ameliorative effects of curcumin against renal injuries mediated by inducible nitric oxide synthase and nuclear factor kappa B during gentamicin-induced toxicity in Wistar rats," European journal of pharmacology, vol. 670, no. 2-3, pp. 578-585, 2011.

[10] A. A. Banday, N. Farooq, S. Priyamvada, A. N. Yusufi, and F. Khan, "Time dependent effects of gentamicin on the enzymes of carbohydrate metabolism, brush border membrane and oxidative stress in rat kidney tissues," Life sciences, vol. 82, no. 9-10, pp. 450-459, 2008.

[11] R. K. Muslih, M. S. Al-Nimer, and O. AL-ZAMELY, "The level of malondialdehyde after activation with (H2O2) and (CuSO4) and inhibition by desferoxamine and molsidomine in the serum of patients with acute myocardial infarction," National journal of chemistry, vol. 5, pp. 139-148, 2002.

[12] S. El Badwi, A. Bakhiet, and E. Abdel Gadir, "Haemato-biochemical Effects of aqueous extract of Khaya senegalensis stem bark on Gentamicin-Induced Nephrotoxicity in Wistar Rats," J. Biol. Sci, vol. 12, pp. 361-366, 2012.

[13] A. E. R. A. Ashour, M. M. Yassin, N. M. A. AASI, and R. M. Ali, "Blood, serum glucose and renal parameters in lead-loaded albino rats and treatment with some chelating agents and natural oils," Turkish journal of Biology, vol. 31, no. 1, pp. 25-34, 2007.

[14] R. Abdelrahman, "Protective effect of apocynin against gentamicin-induced nephrotoxicity in rats," Human \& experimental toxicology, vol. 37, no. 1, pp. 27-37, 2018.

[15] U. Rashid and M. R. Khan, "Fagonia olivieri prevented hepatorenal injuries induced with gentamicin in rat," Biomedicine \& Pharmacotherapy, vol. 88, pp. 469-479, 2017.

[16] M. A. Algridi and A. E. Azab, "Amelioration of Gentamicin Induced Dyslipidemia in Guinea Pigs by Curcumin and Rosemary," Scientific Review, vol. 3, no. 2, pp. 6-16, 2017.

[17] B. Ali, A. A. Gayoum, and A. Bashir, "Gentamicin nephrotoxicity in rat: some biochemical correlates," Pharmacology \& toxicology, vol. 70, no. 6, pp. 419-423, 1992.

[18] G. Tong, Y. Zhang, Y. Zhang, H. Li, and J. Liu, "Effect of celery seed extract on hyperuricemia in rats," Food Sci, vol. 12, p. 152, 2008. 